\title{
Articulação intersetorial como estratégia de gestão na Política de Segurança Alimentar e Nutricional no Brasil: análise do Programa Cozinha Comunitária
}

\author{
Narjara Incalado Garajau ${ }^{1}$ e Maria Lúcia Miranda Afonso ${ }^{2}$
}

Insegurança alimentar, fome e falta de acesso à alimentação adequada são fenômenos complexos que vão além da escassez de alimentos. Seu enfrentamento requer a articulação entre as diferentes políticas públicas e setores sociais, adotando uma nova abordagem de gestão dos programas sociais de segurança alimentar. Pretende-se discutir a intersetorialidade como uma estratégia de gestão no contexto da Política Nacional de Segurança Alimentar e Nutricional, que visa assegurar o Direito Humano à Alimentação Adequada por meio de programas como o Programa Cozinha Comunitária. Uma pesquisa quanti-qualitativa foi realizada no município de Contagem (MG), incluindo a aplicação de formulários a 128 beneficiários e a realização de entrevistas qualitativas semiestruturadas com gestores e técnicos. Os resultados quantitativos apontaram que os beneficiários tinham renda média abaixo de um salário mínimo, com predominância da inserção feminina e tempo médio de vinculação ao programa de 12 meses. A análise das entrevistas mostrou que a intersetorialidade apresenta-se como uma perspectiva inovadora na gestão do Programa Cozinha Comunitária, viabilizando uma nova relação entre os beneficiários e os gestores, visando à garantia do direito humano à segurança alimentar.

Palavras-chave: Insegurança Alimentar; Gestão Social; Intersetorialidade; Política Nacional de Segurança Alimentar e Nutricional; Programa Cozinha Comunitária.

\section{Intersectorality as a management strategy for the Food and Nutrition Security Policy in Brazil: analysis of the Community Kitchen Program}

Food insecurity, hunger, and lack of access to adequate food are complex phenomena that go beyond food shortages. Coping strategies for these phenomena require the coordination among the various public policies and social sectors, adopting a new approach to the management of social programs on food security. The paper discusses the intersectorality as a management strategy in the context of the National Policy for Food and Nutrition Security, aimed to ensure the human right to adequate food through programs such as the Community Kitchen Program. A quanti-qualitative research was conducted in the city of Contagem (MG), including a survey with the social program beneficiaries and semi-structured qualitative interviews with technicians and managers. The quantitative results showed that the beneficiaries had an average income below the minimum wage, with a predominance of female insertion, and an average time of 12 months of participation in the program. The analysis of the interviews showed that the intersectorality is an innovative approach to the management of the Community Kitchen Program, enabling the construction of new relationship between beneficiaries and managers to ensure the right to food security.

${ }^{1}$ Professora do Curso de Graduação em Serviço Social, Centro Universitário UNA - Belo Horizonte. Endereço para correspondência: Rua do Registro, no 750, Bloco B, Casa 10, Bairro Centro, Contagem, Minas Gerais, CEP: 32017-390. Telefone: +55 (31) 9713-0030/(31) 9149-6933. E-mail: narjara_garajau@yahoo.com.br

${ }^{2}$ Professora do Curso de Mestrado em Gestão Social, Educação e Desenvolvimento Local (Mestrado Profissional e Interdisciplinar) - Centro Universitário UNA. Endereço para correspondência: Rua Dr. Sette Câmara, no 396, apto. 502, Bairro Luxemburgo, Belo Horizonte, Minas Gerais, CEP: 30380-360. Telefone: +55 (31) 99613-8057. E-mail: luafonso@yahoo.com 
Keywords: Food Insecurity; Social Management; Intersectorality; National Policy for Food and Nutrition Security; Community Kitchen Program.

\section{INTRODUÇÃO}

Este artigo aborda a intersetorialidade como uma estratégia de gestão que, se inserida na Política Nacional de Segurança Alimentar e Nutricional (PNSAN), poderia tornar mais eficazes, quanto aos resultados pretendidos, bem como mais efetivas as ações e programas relacionados à segurança alimentar. Em uma sociedade desigual e excludente, a insegurança alimentar está diretamente relacionada ao sistema social, atingindo uma parcela significativa da população brasileira em situação de vulnerabilidade social.

Considerando que o Estado deve reconhecer, respeitar, proteger, promover e prover a Segurança Alimentar, para garantir o Direito Humano a Alimentação Adequada (DHAA), os moldes de gestão tradicionais devem ser reavaliados, uma vez que este tipo de gestão, com tendências à centralização, compromete a participação e o empoderamento dos cidadãos. Compreende-se que as formas tradicionais de gestão, centradas no modelo burocrático, apresentam limites na operacionalização de programas e políticas, comprometendo $\mathrm{O}$ atendimento às diferentes demandas sociais, sendo uma destas a alimentação.

O DHAA é responsabilidade e obrigação do Estado, que deve desenvolver ações que garantam o acesso aos alimentos para os que se encontram em situação de vulnerabilidade social. A garantia deste direito requer ainda a responsabilidade da sociedade civil em participar, controlar e fiscalizar as ações e serviços prestados.

Visando contribuir para esta discussão, foi realizada, em 2012, no município de Contagem (MG), uma pesquisa quanti-qualitativa sobre o Programa Cozinha Comunitária, um dos principais programas da Política Nacional de Segurança Alimentar e Nutricional. Buscou-se compreender a percepção dos usuários, técnicos e gestores sobre o programa, bem como a relevância da articulação intersetorial como estratégia para a sua gestão.
O presente artigo parte de uma discussão sobre a insegurança alimentar e a fome como violações de direitos. Oferece uma breve reconstrução histórica do reconhecimento do Direito Humano à Alimentação Adequada que resultou na Política Nacional de Segurança Alimentar e Nutricional e é feita uma revisão do Programa Cozinha Comunitária. Em seguida, apresenta-se a pesquisa, sua metodologia, principais resultados e conclusões. Apresenta-se uma reflexão sobre os desafios para a incorporação da intersetorialidade na efetivação de programas na área da segurança alimentar.

\section{Considerações sobre a Insegurança Alimentar como violação de direitos}

Sentir fome está relacionado com a insegurança alimentar, que por sua vez viola o direito humano de alimentar adequadamente. $\mathrm{O}$ estado nutricional do cidadão, muitas vezes, está ligado diretamente ao seu posicionamento na estrutura social, fator este relacionado ao sistema social, no qual a desigualdade é notória. A relação entre pobreza e o estado de insegurança alimentar integra o cotidiano de uma parcela significativa da população brasileira, que encontra-se em situação de vulnerabilidade social. Ressalta-se que a falta de acesso aos bens e aos direitos sociais se faz determinante para a condição de insegurança alimentar ${ }^{[1]}$.

De acordo com Burity et al. ${ }^{[2]}$, a insegurança alimentar pode-se manifestar de duas formas: insegurança alimentar relativa, quando há o comprometimento da qualidade nutricional mesmo com a oferta de quantidade de alimentos; e insegurança alimentar absoluta, quando há indisponibilidade quantitativa e qualitativa de alimentos, por períodos curtos ou longos, muitas vezes levando ao estado de fome e desnutrição.

Considera-se que a expressão mais grave da insegurança alimentar é a fome, que engloba fome crônica, como questão social ligada aos desequilíbrios estruturais da sociedade, e que só será efetivamente combatida por meio de políticas públicas estruturais. 
Utilizou-se o conceito de Abramovay ${ }^{[3]}$ para conceituar que a fome é, "um fenômeno quantitativo, que pode ser definido como a incapacidade da alimentação diária fornecer um total calórico correspondente ao gasto energético realizado pelo trabalho do organismo".

Enfrentar o quadro de insegurança alimentar engloba vários aspectos, sendo relevante destacar o aumento da disponibilidade de renda da população e intervenção do Estado por meio de programas que garantam o acesso à alimentação. $\mathrm{O}$ compromisso político de forma integrada deve ser constante para que se considere possível à redução da fome.

A discussão sobre a Segurança alimentar não é algo recente. Seu conceito é originário da Europa, a partir da primeira guerra mundial (1914-1918). Neste período, o enfoque estava na capacidade de cada país de produzir sua própria alimentação, garantindo a sua manutenção e evitando estar vulnerável a possíveis embargos devido a razões políticas ou militares. A partir da segunda guerra (1939-1945), a questão da segurança alimentar adquiriu uma perspectiva internacional com a criação da Organização das Nações Unidas (ONU), e da Organização das Nações Unidas para a Agricultura e a Alimentação (FAO), ambas fundadas em 1945. Passase, então, a tratar a insuficiência de disponibilidade de alimentos por meio das iniciativas de assistência alimentar aos países pobres a partir do excedente de produção dos países ricos.

Por meio da Declaração Universal dos Direitos Humanos, 1948, há o reconhecimento da dignidade inerente à pessoa humana e de seus direitos fundamentais sendo inalienáveis, conforme destaca o artigo que inclui a alimentação:

Art. 25 - Todo homem tem direito a um padrão de vida capaz de assegurar a si e a sua família saúde e bem estar, inclusive alimentação, vestuário, habitação, cuidados médicos e serviços sociais indispensáveis e direito a segurança em caso de desemprego, doença, invalidez, viuvez, velhice ou outros casos de perda dos meios de subsistência em circunstâncias fora de seu controle. [4]

Reconhecido como direitos intrínsecos ao ser humano, os Direitos Humanos visam proteger a dignidade, justamente por isso, devem ser "garantidos" e não "concedidos" pelo Estado. Quando um direito passa a ser historicamente compreendido como essencial para a proteção da dignidade, ele deve ser garantido pela lei, pelo Estado e pela sociedade. Esse é o caso do Direito Humano à Alimentação Adequada, pois este não existindo, não existirá tampouco o direito à vida nem a cidadania poderá ser exercida em suas funções mais básicas.

No contexto brasileiro, ações voltadas para a segurança alimentar remontam à década de 1940, no âmbito do Ministério do Trabalho, com a criação, em 1939, do Serviço Central de Alimentação no IAPI Instituto de Aposentadoria e Pensão dos Industriários, que foi substituído pelo Serviço de Alimentação da Previdência Social (SAPS), que objetivava a melhoria da alimentação do trabalhador no Brasil. Porém, conforme analisa Burity ${ }^{[2]}$ et al, o aumento de produção que ocorreu na década de 1960 e teve continuidade em 1980 não beneficiou a população, pois permanecia vinculado aos interesses industriais e capitalistas. Evidente assim, que a insegurança alimentar devia-se à falta de garantia de acesso físico e econômico aos alimentos, em decorrência da exclusão social e que programas não eram voltados para todos os segmentos que necessitavam.

Consolidado este argumento na Conferência Internacional de Nutrição, realizada em Roma, em 1992, pela FAO e pela Organização Mundial da Saúde, em que o reconhecimento internacional teria um impacto sobre as políticas nacionais no que dizia respeito à insegurança alimentar.

No Brasil, como resultado da pressão política interna e externa, amplia-se a discussão sobre segurança alimentar a partir da segunda metade da década de 80 , incorporando a ideia da necessária intervenção do Estado para garantir o DHAA. A esse respeito:

\footnotetext{
Como provedor, o Estado deve criar as condições - compra e distribuição direta dos serviços, pagamento indireto ou subsídios - para que a sociedade possa receber os bens e serviços produzidos pela sociedade que não podem se submeter ao mercado. Finalmente, como regulador, o Estado deve controlar as relações econômicas e sociais, de modo a assegurar o desenvolvimento sustentável e a qualidade de vida, normalmente inconsistente com as sinalizações do mercado. [5]
}

Neste período, a iniciativa do Ministério da Agricultura reduzia-se à avaliação do estado nutricional dos indivíduos, principalmente no que se referia à desnutrição infantil. Conforme relata Burity et al. [2], as 
sementes para a proposta da Política Nacional de Segurança Alimentar e Nutricional foram lançadas, primeiramente, por um documento técnico no Ministério da Agricultura, em 1985, intitulado Segurança Alimentar - proposta de uma política de combate à fome, e em seguida, em 1986, nas declarações da I Conferência Nacional de Alimentação e Nutrição, que teve a participação da sociedade civil e reafirmou a noção de segurança alimentar, do ponto de vista nutricional e do ponto de vista dos direitos.

Destaca-se que a organização não governamental Instituto da Cidadania lançou, em 1991, o documento que seria a base para um programa de segurança alimentar e nutricional e que serviu à proposta de uma Política Nacional de Segurança Alimentar. Uma intervenção eficaz, nessa época, foi a publicação do Mapa da Fome no Brasil, em 1993, pelo Instituto de Pesquisa Econômica Aplicada (IPEA). Estas ações concorrem para o estabelecimento, em 1993, do Conselho Nacional de Segurança Alimentar (CONSEA).

Faz-se necessário ressaltar a mobilização da população brasileira no enfrentamento da fome no ano de 1994, em julho quando ocorreu a I Conferência Nacional de Segurança Alimentar, impulsionada por vários setores. Houve a elaboração de um documento brasileiro dirigido à Cúpula Mundial da Alimentação, por uma comissão tripartite (governo, sociedade civil e iniciativa privada) realizada em Roma, em 1996. Este foi um momento de reconhecimento da mobilização social pela Segurança Alimentar e Nutricional no Brasil. Essa mobilização resultou na criação do Fórum Brasileiro de Segurança Alimentar e Nutricional (FBSAN), no ano de 1998, constituindo uma rede nacional que congrega organizações sociais, pesquisadores e técnicos governamentais, com ramificações na forma de fóruns estaduais.

Como resultado de toda a mobilização política no âmbito da sociedade civil, do Estado e das influências internacionais, a Política Nacional de Alimentação e Nutrição foi instituída por meio da portaria no 710 de junho de 1999, contendo as diretrizes programáticas que tiveram como princípio norteador, o Direito Humano à Alimentação Adequada e a Segurança Alimentar e Nutricional.
Não se trata de intervir por razões filantrópicas ou humanitárias. Trata-se do reconhecimento do Direito Humano à Alimentação Adequada (DHAA) como parte do conjunto de direitos humanos, historicamente reconhecidos e constituídos, que devem ser respeitados, promovidos, protegidos e defendidos pelo Estado e pela sociedade. A fome e a insegurança alimentar não são apenas calamidades, são violações de direitos.

O FBSAN ampliou-se, agregando várias entidades afiliadas, tendo desempenhado papel destacado na recriação do CONSEA em 2002, bem como na composição da agenda do Conselho e na articulação com outras redes que mantêm interfaces com a SAN como: reforma agrária, economia solidária, agroecologia, povos indígenas, populações tradicionais, etc. A partir deste ano foi criado um o Ministério Extraordinário de Segurança Alimentar e Combate à Fome (MESA), responsável pela condução do então Programa Fome Zero, com o objetivo de enfrentar a fome no país.

Em 2003, é criado o Programa Fome Zero, sendo elaborado e dirigido pelo MESA. Em janeiro de 2004, institui-se o Ministério do Desenvolvimento Social e Combate à Fome (MDS), integrando as ações do Ministério de Assistência Social, do Ministério Extraordinário de Segurança Alimentar e Combate à Fome e da Secretaria-Executiva do Programa Bolsa Familia. A II Conferência Nacional de SAN, realizada em Olinda (PE), em 2004, ampliou o conceito de Segurança Alimentar e Nutricional:

\footnotetext{
Segurança Alimentar e Nutricional consiste na realização do direito de todos ao acesso regular e permanente a alimentos de qualidade, em quantidade suficiente, sem comprometer o acesso a outras necessidades essenciais, tendo como base práticas alimentares promotoras de saúde que respeitem a diversidade cultural e que seja ambiental, cultural, econômica e socialmente sustentável [2]
}

Todo esse arcabouço de programas e legislações contribuiu para a consolidação da Política de Segurança Alimentar e Nutricional, pois, fazia-se necessário um novo redirecionamento no trato da insegurança alimentar, no combate a fome. Nesse momento que se coloca a necessidade de se estruturar a intervenção do Estado na área da SAN por meio de ações intersetoriais. A amplitude e a complexidade do problema da fome demandam a ação integrada das 
diversas políticas públicas e atores da sociedade civil. Além disso, a necessidade de organização das ações em nível local estava bastante evidente, sendo a fome um fenômeno a ser combatido localmente, através de ações tanto emergenciais quanto sustentáveis.

Com a PNSAN, o Estado passa a assumir a responsabilidade pelo combate a fome no país. Estados e Municípios, sob a autoridade do Governo Federal e cobrados pela mobilização da sociedade civil são chamados a se posicionar perante a problemática da insegurança alimentar no Brasil. Decorrem daí várias iniciativas, planos e ações, em nível local, no intuito de explicitar e redefinir o papel do Estado, da sociedade civil e do mercado na garantia da segurança alimentar. Também foram instituídos mecanismos de exigibilidade, reconhecendo a alimentação adequada com um direito do cidadão. Nesta nova proposta, o princípio da intersetorialidade surge como parte fundamental dos próprios documentos oficiais, ou seja, como concepção de política pública:

A construção do Sistema e da Política de SAN visa promover a intersetorialidade das ações e programas públicos e a participação social, sendo coordenados pelo CONSEA e pela Câmara Interministerial de Segurança Alimentar e Nutricional (CAISAN), desdobrando-se nas esferas estadual e municipal; ela inclui a mobilização do marco legal existente, sendo a principal a Lei. [6]

A evolução dos conceitos de Segurança Alimentar e Nutricional (SAN) e do Direito Humano à Alimentação Adequada no Brasil, foi paulatinamente construída como garantia de direitos e de efetivação da cidadania. Resulta de um movimento histórico e um dos seus marcos foi a aprovação, em fevereiro de 2010, da proposta de Ementa Constitucional que inclui a alimentação entre os direitos sociais da Constituição Federal:

São direitos sociais a educação, a saúde, a alimentação, o trabalho, a moradia, o lazer, a segurança, a previdência social, a proteção à maternidade e à infância, a assistência aos desamparados, na forma desta Constituição. [7]

Sublinhe-se que um direito tão básico que se mescla ao próprio direito de sobrevivência só foi formalmente incorporado ao texto constitucional mais de 20 anos depois de sua promulgação. Contudo, além das normativas, devem ser estabelecidas ações e estratégias para conseguir garantir esse direito. Percebe- se nas ações intersetoriais uma possibilidade de efetivar ações possíveis como elemento importante nos documentos oficiais da PNSAN. No item a seguir, destaca-se uma breve revisão do conceito para que possa ser analisado na correlação da intersetorialidade no Programa Cozinha Comunitária.

\section{A Política de Segurança Alimentar e a Intersetorialidade}

Pertinente destacar que, a partir da promulgação da Constituição Cidadã de 1988, o processo de redemocratização do Brasil passa a exigir o reordenamento da gestão das políticas públicas, a fim de maximizar a capacidade dos serviços para garantir os direitos sociais. Reafirma a autonomia do governo municipal, como afirma Junqueira [8], “o poder municipal no Brasil tem como competência organizar e prestar, diretamente ou sob o regime de concessão ou permissão, os serviços públicos de interesse local. $\mathrm{O}$ exercício dessas competências tem relação direta com a garantia dos direitos sociais aos cidadãos". O reordenamento da administração municipal contribuiu para desnudar muitos limites das formas tradicionais de gestão nas políticas públicas do estado democrático, isto devido à falta de integralidade das ações, à ausência da participação popular, à forma de gestão centralizada, verticalizada, setorializada e sem proposta de articulação de rede de serviços. A esse propósito, é importante ressaltar:

\begin{abstract}
As estruturas setorializadas tendem a tratar o cidadão e os problemas de forma fragmentada, com serviços executados solitariamente, embora as ações se dirijam à mesma criança, à mesma família, ao mesmo trabalhador e ocorra no mesmo espaço territorial e meio-ambiente. Conduzem a uma atuação desarticulada e obstaculizam mesmo os projetos de gestões democráticas e inovadoras ${ }^{[8]}$
\end{abstract}

A estratégia de gestão com ênfase na intersetorialidade requer a integração das políticas e programas setoriais, os setores do governo, da sociedade civil e do mercado, destacando-se como um novo arranjo institucional e organizacional necessário, principalmente em programas de âmbito municipal. Desde modo, o trabalho intersetorial supõe não apenas o diálogo ou o trabalho simultâneo entre os atores envolvidos, mas principalmente a busca por resultados integrados [9], estando à ênfase posta no desenvolvimento local e visando qualidade de vida para os cidadãos. 
As formas de gestão tradicionais encontram sérias limitações quanto à oferta de serviços assim como à sua execução, devido a diversos aspectos como a hierarquização, a setorialização e fragmentação. As políticas públicas desarticuladas não atingem os mais graves e complexos problemas vivenciados por uma parcela significativa da população brasileira, como é o caso do fenômeno da fome.

A gestão social surge como um processo a ser construído com a participação de diversos atores. "Nesta visão, o Estado é visto como articulador necessário e insubstituível, mas não como promotor primordial e exclusivo do desenvolvimento" " 10$]$. Esta é uma construção recente, que poderá introduzir, na sociedade brasileira, uma nova ótica de análise para o social que compreende as demandas e das necessidades dos cidadãos. Traz consigo algumas abordagens e incorpora algumas estratégias, como a descentralização, a participação, o controle social e a intersetorialidade.

Esta estratégia de gestão social inclui um conjunto de processos sociais com potencial viabilizador do desenvolvimento societário emancipatório e transformador [11]. Funda-se em valores, práticas e formação na democracia e da cidadania, em vista do enfrentamento às expressões da questão social como a desigualdade social e o grande contingente populacional que se encontra em situação de vulnerabilidade social no Brasil. Ações e estratégias de enfrentamento a questão da insegurança alimentar tornam-se crucial um efetivo posicionamento do Estado. Aponta-se a questão social como a expressão concreta entre a contradição do capital e o trabalho, que gera uma série de manifestações e expressões como a desigualdade, pobreza, exclusão, dentre outros. Este modelo de gestão apresenta como possibilidade o enfrentamento a estas expressões visando à garantia dos direitos a partir de um novo padrão de civilidade.
No contexto dos fundamentos da política brasileira a intersetorialidade apresenta-se como uma perspectiva inovadora na gestão pública no que tange a condução e operacionalização dos serviços ofertados, na reorganização da gestão, viabilizando que ocorra uma nova relação entre o munícipe, os gestores, considerando-se as peculiaridades locais.

Considera-se, neste artigo, que a intersetorialidade é um processo de operacionalização da gestão social fundamentado em práticas de formação para a democracia e a cidadania bem como na garantia dos direitos, a partir da articulação do trabalho em rede, valorizando diferentes saberes e experiências para a realização e a avaliação de políticas públicas, programas e projetos, dentro de um planejamento articulado e visando resultados sinérgicos e integrados.

A Figura 1 apresenta o que se entende como dimensões da intersetorialidade, buscando identificar as correlações necessárias ao trabalho em rede. 
Figura 1. Dimensões da intersetorialidade

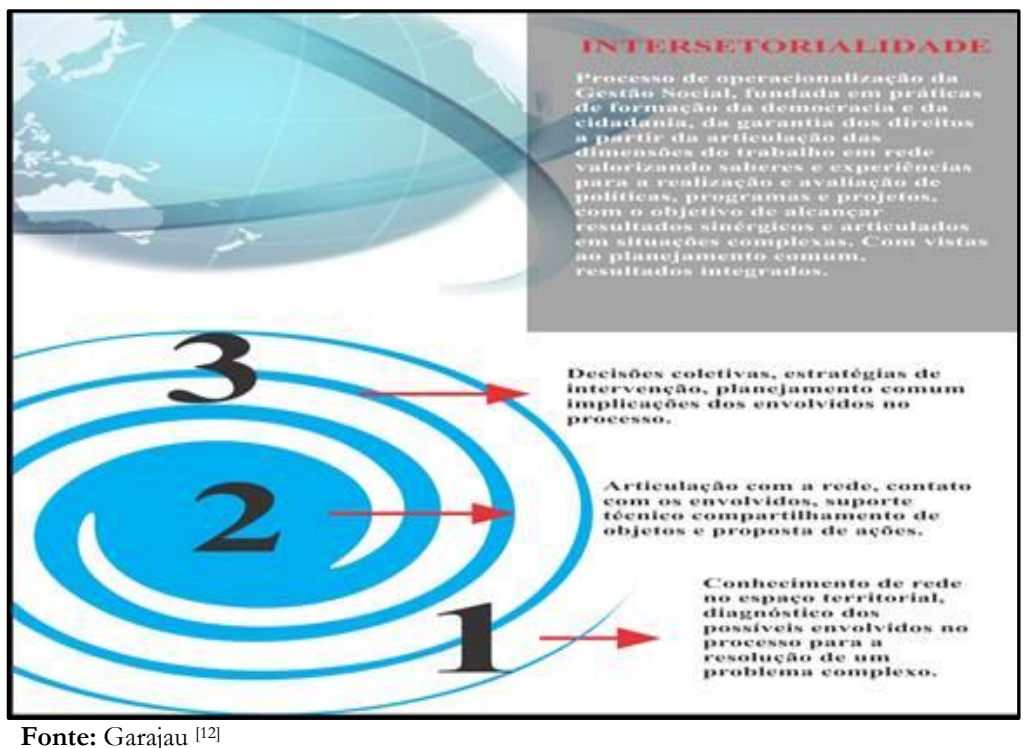

Desmembrar o conceito e suas implicações permite analisar o processo, considerando que $\mathrm{o}$ trabalho em rede é precursor da efetivação deste processo e que a sua execução institui-se por estas três dimensões, importantes para o desenvolvimento intersetorial [12].

A intersetorialidade terá sua efetividade a partir do diálogo, envolvimento, interface, conexão, participação, e isso supõe articulação em rede. Uma estratégia primordial dá-se por meio do diagnóstico ou mapeamento da rede por permitir que se desenvolva o conhecimento transversal dos possíveis envolvidos no processo para a implementação de uma ação intersetorial. Ou seja, é um nível básico de funcionamento que servem de base para um possível planejamento integrado e articulado. Este nível de articulação permite o conhecimento dos envolvidos, a proximidade com os sujeitos que pactuam do mesmo processo social para que possam contribuir na resolução da questão posta para intervenção.

$\mathrm{Na}$ segunda dimensão, a partir do conhecimento desenvolvido na primeira, deve se estabelecer contatos e estreitar relações visando buscar suporte para projetar ações comuns; definir possibilidades de intervenções, dialogar, pactuar funções e diretrizes. Trata-se de construir estratégias para eventuais ações comuns de acordo com a demanda expressa.

Já na terceira dimensão, a objetividade na execução deve se fazer presente, posto que, traçadas as duas dimensões anteriores (o mapeamento e a articulação), é possível executar e planejar o papel de cada um dos envolvidos e gerar decisões coletivas, planejamento integrados e atividades continuadas com os atores envolvidos no desenvolvimento da ação em si, na busca da efetivação de ações integradas.

Para a execução desta estratégia de ação, é pertinente obter conhecimentos e informações quanto à rede de serviços disponíveis (podendo ser serviços públicos, não governamentais, oriundos de associações, movimentos sociais, e até mesmo o mercado). Sublinha-se que a gestão intersetorial pode ter operacionalização diferenciada e sua materialização conta com o envolvimento da rede de serviços, sujeitos responsáveis.

Problemas complexos, como é o caso da insegurança alimentar e do fenômeno da fome, a intersetorialidade se anuncia como estratégia de gestão viável. Deve se apoiar na articulação possível, dentro da especificidade de cada contexto social e histórico, entre os diversos atores sociais (gestores, técnicos e beneficiados), promovendo o desenvolvimento local 
por meio do trabalho seguindo as dimensões da execução das atividades em rede. A PNSAN incorpora a intersetorialidade como estratégia de gestão desta política, compactuando que a intervenção no âmbito da insegurança alimentar deve ser efetivada por diversos atores.

Evidencia-se que o processo de gestão com indicadores para a efetivação de ações intersetoriais, apresenta-se com estratégias em nível macro e microssocial. No âmbito macro destaca-se um viés de gestão amplo, com articulações interministeriais, ou entre governos e diversos setores, no nível microssocial apresentação o resultado integrado e sinérgico na resolução de complexos sociais no âmbito local. Deste modo, analisar-se-á o Programa Cozinha Comunitária, idealizado para ser um equipamento que busca garantir o direito à alimentação adequada. A criação deste programa contempla, em sua constituição, a implementação de uma rede de proteção nas localidades com altos índices de vulnerabilidade.

\section{O Programa Cozinha Comunitária}

Inserido na Política Nacional de Segurança Alimentar, o Programa Cozinha Comunitária foi idealizado para ser um equipamento que busca garantir a alimentação adequada às pessoas em situação de vulnerabilidade social. De acordo com a cartilha do Ministério do Desenvolvimento Social e Combate à Fome:

\footnotetext{
O Projeto de incentivo à instalação de Cozinhas Comunitárias faz parte do conjunto de ações voltadas para garantir o direito humano à alimentação adequada, combatendo a insegurança alimentar que atinge parcela considerável da população do País. [13]
}

A criação deste programa contempla, em sua constituição, a implementação de uma rede de proteção nas localidades com altos índices de vulnerabilidade:

A criação de Cozinhas Comunitárias visa implementar uma rede de proteção alimentar, em locais onde existam segmentos mais vulneráveis à fome, como familias pobres, trabalhadores formais e informais de baixa renda, desempregados, estudantes, idosos, possibilitando-lhes o acesso a refeições balanceadas e de qualidade oriundas de processos seguros. ${ }^{[13]}$
Detalhando o referido programa, para a sua efetivação, há uma contrapartida entre União e Municípios, a título de cooperação. A União preconiza nacionalmente as condicionalidades, critérios e contrapartidas que o município deve oferecer para que seja enviado o recurso para a gestão do programa. Logo, compete ao município ofertar o serviço, delimitar a área de vulnerabilidade em que este equipamento será locado, assim como a contratação da equipe técnica, a manutenção do programa e o fornecimento dos alimentos. O programa é uma unidade de alimentação e nutrição que deverá ter uma produção mínima de duzentas refeições por dia, em funcionamento pelo menos cinco dias da semana. A equipe preconizada pelo Ministério do Desenvolvimento Social envolve a contratação de: um nutricionista; dois cozinheiros e três auxiliares de cozinha ${ }^{[13]}$.

O público-alvo deste programa são pessoas em situação de insegurança alimentar, preferencialmente aquelas indicadas pelas equipes técnicas dos Centros de Referência da Assistência Social (CRAS), equipamento este vinculado a proteção social básica da Política Nacional de Assistência Social. As unidades são instaladas em regiões socialmente vulneráveis, com baixo Índice de Desenvolvimento Humano (IDH), situados em periferias e regiões metropolitanas. Após a implantação das unidades, os governos estaduais e municipais assumem a gestão dos serviços, podendo, para isso, firmar parcerias com organizações comunitárias e entidades sociais ligadas a programas de geração de trabalho e renda [13].

A PNSAN preconiza que se efetivem a promoção de ações intersetoriais em seu direcionamento. Entretanto, pode-se indagar que fatores podem facilitar ou dificultar, em nível local, a implementação da intersetorialidade, pois, esta não é uma estratégia que irá ocorrer espontaneamente. 
De fato, a intersetorialidade poderia contribuir, na prática, não apenas para uma maior eficácia na garantia do DHAA, mas, também, para ações de inclusão social dos usuários na rede de serviços, considerando um conjunto de direitos a serem respeitados, promovidos e defendidos.

O município de Contagem aderiu à execução do Programa Cozinha Comunitária, que integra conjunto de ações da PNSAN, idealizado para ser um equipamento que busca garantir a alimentação adequada aos que dela necessitam. A criação deste programa contempla, em sua constituição, a implementação de uma rede de proteção nas localidades com altos índices de vulnerabilidade. Contagem é um município de médio porte que localizase na região metropolitana de Belo Horizonte. No marco legal do município consta a Lei no 4276/2009, que cria o Sistema Municipal de Segurança Alimentar e Nutricional Sustentável (SIMSANS), e estabelece critérios de gestão participativa, visando efetivar a segurança alimentar por meio da articulação permanente com os diversos setores que compõem a rede de atendimento. A legislação prevê a instituição de um comitê intersetorial para elaborar estratégias de garantia do DHAA.

A gestão da segurança alimentar se organiza a partir do funcionamento do Conselho Municipal de Segurança Alimentar e Nutricional (COMSAN); do Conselho Gestor das Cozinhas Comunitárias; do Centro Municipal de Agricultura Urbana e Familiar (CMAUF); Grupo de trabalho de SAN; Comitê Gestor da Coordenadoria de Segurança Alimentar Nutricional Sustentável (CSANA); conferência Municipal de SAN.

O decreto municipal no 1.860 , de 30 de maio de 2012, institui o Comitê Intersetorial de Segurança Alimentar e Nutricional Sustentável com a finalidade de promover a articulação e a integração dos órgãos e entidades da administração pública municipal afetos à área de segurança alimentar e nutricional. Tem como intuito promover canais para o exercício de atuação integrada dos órgãos públicos municipais que interagem com o tema de Segurança Alimentar e Nutricional Sustentável, visando à transversalização das ações no desenvolvimento das políticas públicas municipais correlatas. Torna-se um avanço a legitimação deste Plano ao traçar as diretrizes da operacionalização da política de segurança alimentar, devido à proposta inovadora em articular a gestão. Sua matriz operacional apresenta as prioridades pactuadas entre o grupo de trabalho contendo ações, atividades, delegando os responsáveis e os prazos a serem executados.

Objetivando compreender as articulações e o desenvolvimento deste programa, foi desenvolvida a pesquisa sobre o Programa Cozinha Comunitária em Contagem, com ênfase na gestão social e intersetorialidade. Em seguida, serão apresentados os procedimentos metodológicos e resultados da pesquisa.

\section{METODOLOGIA}

Elegeu-se o programa Cozinha Comunitária, como campo de investigação para análise da operacionalização da intersetorialidade na PNSAN, em nível municipal. Delimitou-se, então, dois equipamentos que funcionavam em regiões distintas do município, os bairros Nacional e Nova Contagem. A pesquisa foi realizada em três fases, com técnicas diferenciadas de coleta de dados a partir de uma abordagem quali-quantitativa. Os sujeitos da pesquisa foram: a coordenadora do programa Cozinha Comunitária; gestores do município de Contagem (secretarias); uma nutricionista (técnica responsável do programa); uma assistente social (técnica referência do programa) e beneficiados do programa.

Na primeira fase da pesquisa, foram realizadas entrevistas semi-estruturadas, a partir de um temário previamente definido, com a coordenadora e as duas técnicas (assistente social e nutricionista) do Programa Cozinha Comunitária de Contagem. Os temas abordados foram: análise do programa dentro da política nacional de segurança alimentar; o fundamento social e político do programa Cozinha Comunitária; percepção do programa como ação estrutural ou emergencial; efetividade das ações no combate à fome e à superação da pobreza; percepção do lugar ocupado pelo beneficiário no programa; sentido percebido sobre o processo emancipador e de empoderamento das famílias via ações no programa Cozinha Comunitária; estratégias atuais de gestão do programa, com seus entraves e possibilidades; percepção das possibilidades de gestão social do programa; atividades intersetoriais e de trabalho em rede; percepção de parcerias possíveis e necessárias que podem e devem ser construídas para ampliar a gestão social do programa; sugestões de melhoramentos de gestão e ações intersetoriais. 
A segunda fase da pesquisa compreendeu as entrevistas com os gestores das secretarias que compõem o Plano Integrado de Segurança Alimentar Nutricional e Sustentável de Contagem. Estas secretarias são: Desenvolvimento Social; Saúde; Educação e Cultura; Defesa Social; Direitos e Cidadania; Adjunta de Limpeza Urbana; Desenvolvimento Urbano; Governo; Administração Planejamento; Meio Ambiente; Trabalho e Geração de Renda.

As entrevistas foram realizadas pela pesquisadora, por meio da técnica bola de neve, utilizada para indicadores de amostragem: a partir dos critérios da pesquisa, são definidos os participantes iniciais, que indicam novos entrevistados, os quais, por sua vez, indicam outros e, assim, sucessivamente até que seja alcançado o objetivo proposto. O processo é finalizado quando se alcança o ponto de saturação, ou seja, quando o pesquisador considera que obteve o resultado esperado, pela repetição das informações. Pretendeu-se, com esta estratégia, possibilitar a análise da intersetorialidade, uma vez que os entrevistados indicaram que setores e/ou programas poderiam compor uma rede de trabalho na questão da segurança alimentar. A partir desta indicação, novas entrevistas foram realizadas com os gestores. O temário apontou: o fundamento social e político do programa Cozinha Comunitária; percepção do programa como ação estrutural ou emergencial; percepção das possibilidades de gestão social do programa; atividades intersetoriais e de trabalho em rede; percepção de parcerias possíveis e necessárias que podem e devem ser construídas para ampliar a gestão social e ações intersetoriais.

$\mathrm{Na}$ terceira fase, foram aplicados formulários estruturados com a finalidade de sistematizar as percepções dos beneficiados relativas ao Programa Cozinha Comunitária. Optou-se por trabalhar apenas com usuários na faixa etária entre 18 e 65 anos. A partir de um total de 230 cadastrados neste perfil, delimitouse uma amostra de 128 participantes, com igual número de formulários válidos aplicados, para obtenção de margem de erro de 5\% e nível de confiança de $90 \%$.

\footnotetext{
O formulário foi construído a partir dos seguintes eixos norteadores: condições socioeconômicas (número de pessoas no domicílio, idade e grau de instrução, escolaridade, renda, bens disponíveis no domicilio); familiares que são cadastrados no programa; condições habitacionais; acesso aos serviços da rede social do município
}

(educação, saúde, assistência social); período em que esteve em condições de insegurança alimentar; tempo de participação no programa Cozinha Comunitária; avaliação que faz do programa; percepção das atividades que poderiam compor o programa; percepção do lugar ocupado pelo beneficiário no programa; percepção do processo emancipador e de empoderamento das famílias via ações do programa Cozinha Comunitária.

O formulário foi submetido a um pré-teste inicial e, depois de revisto, foram aplicados por estudantes de graduação em Serviço Social, selecionados pelo Núcleo de Estágio em Serviço Social (NESS), do Centro Universitário UNA. Os acadêmicos receberam treinamento, dado pela pesquisadora, em três encontros, abordando os objetivos e a relevância social da pesquisa, os temas de análise, a abordagem dos participantes, apresentação, leitura e assinatura do TCLE, a apresentação e a aplicação do formulário. A aplicação foi realizada em três dias consecutivos e a pesquisadora coordenou todo o processo, visando garantir a sua qualidade, validade e lisura.

A pesquisa foi aprovada pelo Comitê de Ética do Centro Universitário UNA, estando inscrita na Plataforma Brasil sob o CAAE 01983112.5.0000.5098. Todos os participantes da pesquisa assinaram o Termo de Consentimento Livre e Esclarecido (TCLE).

\section{RESULTADOS}

Dentre os 128 beneficiários que responderam à pesquisa, 92 eram mulheres e 36 eram homens. Examinar esta questão permite enfatizar a presença das mulheres que, tradicionalmente em nossa cultura, assumem a responsabilidade do trato com a família. As mulheres geralmente são usuárias de programas na área alimentar, pois fazem da alimentação dos filhos uma prioridade; assim, é preciso apoiar as mulheres para assegurar a manutenção da família. Não se trata de defender que este cuidado seja prerrogativa somente feminina, mas evidencia-se que, historicamente, a mulher, nas mais diversas faixas etárias, assume esta função social. A idade predominante das entrevistadas foi entre (25 a 64 anos) e o nível de escolaridade fundamental incompleto. 
O propósito do programa é fornecer alimentação preparada para as famílias, almoço e/ou jantar. Além disso, seria importante proporcionar outros meios para que as famílias busquem a melhoria da sua qualidade de vida, seja realizando cursos, retomando estudos, participando de oficinas, qualificando para o trabalho. Para isso, é pertinente oferecer ações intersetoriais para envolver as famílias em atividades que poderiam ser direcionadas dentre as diversas políticas, programas e setores.

Quanto ao tempo de vinculação ao programa, 93 estão cadastrados entre um a doze meses e 35 está há mais de um ano. A proposta é manter o assistido pelo período em que ele e/ou sua família encontram-se em situação de insegurança alimentar até que haja mudança nessa situação, para que possa ser desligado. Considera-se que esta mudança poderia ser alvo de articulação intersetorial, pois se constatou que as famílias cadastradas também estão inseridas em outros programas das secretarias que compõem o Plano Integrado de Segurança Alimentar Nutricional e Sustentável de Contagem.

Diagnosticou-se que, dentre os 114 beneficiários, a renda familiar declarada está entre a média de $\mathrm{R} \$ 200,00$ e $\mathrm{R} \$ 622,00$ (valor salário mínimo em 2012) e somente 14 estão acima de $R \$ 622,00$ reais, média de componentes do grupo familiar de três a oito pessoas. Os dados quanto às condições econômicas do núcleo familiar corroboram com as indicações teóricas que, devido à falta de renda, os sujeitos comprometem o seu padrão alimentar. O grau de carência alimentar depende essencialmente do déficit de renda, evidenciase que o problema da fome como questão social está relacionado a este fator.

\section{Em programas como o Cozinha} Comunitária, que possibilitam o acesso ao DHAA, é perceptível o compromisso na participação do empoderamento e emancipação da família. Conforme argumenta a entrevistada 2, afirmando a mudança que ocorre nos indicadores de insegurança alimentar, "a gente consegue enxergar familias que saíram de situações de desnutrição, situações econômicas que a Cozinha Comunitária pode contribuir neste aspecto".
Ressalta-se que este programa é um dos elementos para este processo de mudança, pois um problema complexo como a insegurança alimentar e/ou fenômeno da fome não deve ser analisado como atribuição e competência de apenas um agente neste contexto. Caindo nas armadilhas de uma análise desse tipo, reforçar-se-ia os moldes de gestão tradicional, na qual cada setor deveria assumir a responsabilidade de suas competências. O modelo de gestão social se opõe ao modelo tradicional pelo processo dialógico e pela participação social que contempla esta maneira de administrar, possibilitando o envolvimento dos demais setores visando o enfrentamento das questões sociais, o que se destacará quanto ao envolvimento dos diversos setores no programa.

Considerou-se pertinente avaliar a compreensão das representantes do programa, referente ao entendimento que elas detinham quanto à percepção dos beneficiários sobre o programa, ou seja, como elas acreditam que os usuários percebem a Cozinha Comunitária. Assim, estas pontuaram:

Nas reuniões eles falam como o programa é bom e como mudou a vida deles. Os depoimentos da mudança dos hábitos alimentares[...] meu filho não comia isso e agora está comendo [12]

Eles avaliam que o programa é bom, pois serve como um refúgio, em uma situação de emergência, quando está passando por dificuldade, fome. Às vezes famílias que tem muitas crianças, são famílias muito extensas ${ }^{[12]}$.

Os demais gestores entrevistados compondo a rede de intervenção identificaram os benefícios da Cozinha Comunitária para a comunidade, apontando até mesmo que deveriam ser levadas as ações para demais localidades no município. Todos afirmam que o equipamento traz uma importante contribuição social para a população assistida, que dá suporte as demais atividades de saúde e assistência. 
O perfil dos participantes da pesquisa evidencia que estes acessam a uma série de serviços e baseado na gestão tradicional, cada qual desenvolve suas atividades e prestam serviços sem correlacionar-se com os demais setores e/ou áreas que prestam atendimento ao mesmo cidadão. Permanecendo com este padrão de atuação, mantêm a reprodução de ações setorizadas e centralizadas, reproduzindo o modelo tradicional de gestão.

Gráfico 1. Serviços públicos acessados

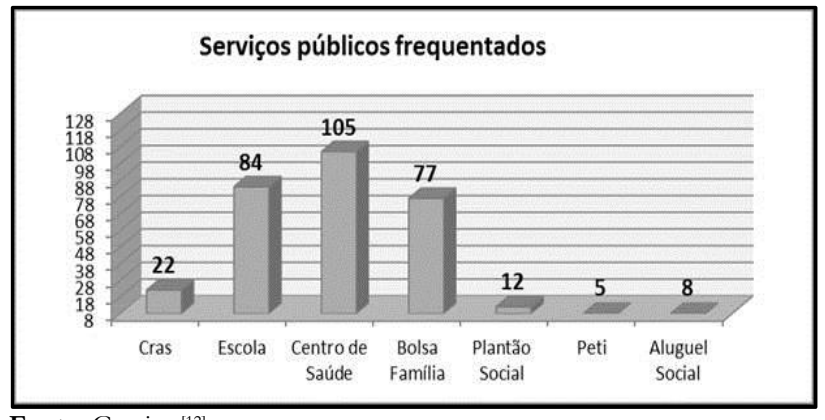

Fonte: Garajau ${ }^{[12]}$

Observa-se que os programas tendem a atender o mesmo público e que estes correm um sério risco da fragmentação da intervenção ou da sobreposição de ações. Isto porque, sem uma articulação entre estas, o desenho das intervenções pode ser semelhante. A estratégia que se anuncia como uma alternativa viável é a ação pautada na intersetorialidade, a partir da construção de estratégias que irão envolver os serviços que atendem e/ou acompanham o mesmo cidadão.

Os técnicos e os gestores de uma maneira geral apontam para um trabalho articulado a partir do momento que desenvolvem reuniões e divulgam ações afins: "contribuímos quando somos acionados para realizar palestras e atividades com os cadastrados no programa" [12].

A proposta de compreender, sistematizar e analisar a efetividade da intersetorialidade pode-se considerar que as percepções que compõe a análise dos técnicos e gestores estão vinculadas a primeira e a segunda dimensão da operacionalização das ações intersetoriais. Recapitulando as dimensões propostas para a efetiva ação intersetorial: a primeira dimensão requer o conhecimento da rede no espaço territorial e o diagnóstico dos possíveis envolvidos em um processo compartilhado; a segunda dimensão envolve a articulação com a rede, estabelecer contato, diálogo, estreitar a comunicação e a parceiras com os envolvidos; a terceira dimensão prevê decisões coletivas, estratégias de intervenção pactuadas, planejamento e previsão de resultados em comum.

Correlacionando as impressões obtidas nas entrevistas e considerando a articulação intersetorial no programa Cozinha Comunitária, percebe-se que as duas primeiras dimensões se efetivam no direcionamento das atividades, conforme declararam os entrevistados. Nota-se que conhecem a rede, o plano integrado de segurança alimentar e deliberam quais são as secretarias que compõem o comitê intersetorial. Os gestores e técnicos têm ciência dos envolvidos que podem ser acionados para a resolução de problemas complexos, apresentam indicadores de articulação da rede, mantêm o contato com os atores envolvidos, fornecem suporte técnico.

Neste estudo, considera-se que a intersetorialidade se efetiva quando se constata a aplicabilidade das três dimensões, ou seja, conhecer a rede e efetivar o diagnóstico dos serviços ofertados, articular a rede e direcionar planejamento e ações integradas, visando resultados comuns. Percebe-se que aspectos que compõem a terceira dimensão não são realizados: as decisões coletivas, as estratégias de intervenção e planejamento em comum e a implicação dos envolvidos no processo. Neste sentido, afirmam os gestores:

\footnotetext{
Não existe um projeto comum nem planejamento integrado nas atividades com as familias. Estamos caminhando para isso, mas não tem nada de concreto. Tem famílias que o CRAS atende e liga para a assistente social e fala que esta família precisa de mais cuidado. Quanto à saúde, já fomos ao posto de saúde e pedimos para encaminhar se souber de alguém em insegurança alimentar [12].
}

Não tem um projeto em comum. Estamos tentando uma parceria com a saúde, para identificar novas famílias com as agentes comunitárias de saúde pelo contato direto que elas têm com famílias que a gente não consegue alcançar. O único objetivo é esse, não tem discussão de casos, das famílias acompanhadas em comum. Não tem projeto integrado. Com o CRAS, tem uma certa parceira, pois muitas são famílias em comum, uma estratégia de referência e contra referência e mais nada [12]. 
Frente ao exposto, é notória a concretização de um movimento preliminar de atendimento que contempla a articulação da rede e a referência em alguns casos, como exemplificada a relação com o CRAS e a saúde. Porém, somente estes aspectos não são indicadores da efetividade de um trabalho intersetorial. O intuito é manter a especificidade de cada setor, mas direcionar as intervenções associando a estratégias de gestão social, efetivando articulações intersetoriais a fim de torná-los interativos e articulados na busca de resolução para problemas complexos na ordem social.

A fragmentação das políticas públicas mostra que, na administração tradicional, os serviços são executados de maneira isolada, cada qual com a uma função específica, de forma que, ainda que sejam direcionados aos mesmos sujeitos, podem resultar em intervenções frágeis, com sobreposição de ações e dificuldades para aferir resultados junto aos beneficiários.

Os serviços não devem somente relacionar entre si, mas integrar, articular, planejar ações para alcançar objetivos comuns. Por meio desta estratégia, consolidaria a efetividade dos trabalhos, ampliaria o conhecimento do poder público dos problemas sociais, promoveria o acesso aos direitos e fortaleceria a sociedade civil como sujeito do processo. Considera-se que, neste formato de gestão as prioridades não teriam o enfoque totalmente setorial, mas seriam definidas a partir dos problemas em comum, cujo direcionamento das intervenções deveria envolver ações integradas dos setores envolvidos.

Especificamente no contexto da insegurança alimentar, correlacionando com os dados coletados na pesquisa, a maioria das famílias assistidas tem na alimentação fornecida pelo programa a sua principal refeição diária, é majoritariamente adulta com baixo nível de escolarização e qualificação profissional, renda familiar predominante abaixo ou até um salário mínimo. Resultado desta combinação, acessar vários programas e serviços ofertados como estratégia de sobrevivência e para garantia da cidadania. Ou seja, os beneficiados fazem parte simultaneamente de uma série de programas e serviços ofertados que não interagem, não relacionam entre si. Os setores assumem o que acreditam ser de sua responsabilidade conduzindo a reprodução de um o modelo tradicional de gestão. "Seria ideal uma gestão intersetorial, por que as mesmas famílias atendidas por nós, são as mesmas atendidas pela saúde, educação e assistência. Teria que ter mais compromisso dos setores envolvidos para dar certo" [12].

Para estes beneficiários não se trata apenas de fornecer a alimentação diária, estes necessitariam ser direcionados a um trabalho intersetorial que contemplasse um planejamento integrado, articulando os serviços na elaboração de um diagnóstico e na projeção de ações em comum. Ressalta-se que o Programa mantém sua função assistindo a aqueles em condições de insegurança alimentar, fornecendo alimentação em quantidade e qualidade aos cadastrados. A não implementação de ações intersetoriais não comprometem o serviço, o que está em análise nesta discussão, é o atendimento que poderia ser disponibilizado pela rede ampliando o fortalecimento dos direitos sociais.

\section{CONCLUSÕES}

Compete à Política Nacional de Segurança Alimentar e Nutricional possibilitar que a população em situação de vulnerabilidade e risco social tenha acesso ao direito humano à alimentação adequada. Contudo, para que se efetive esta função, identifica-se a necessidade da reconfiguração da gestão na esfera pública, incluindo o âmbito municipal, abrangendo a avaliação das formas de organização e de regulação dos serviços prestados, caracterizando um novo relacionamento entre governo, sociedade civil e mercado, bem como focalizando o desenvolvimento social.

A intersetorialidade surge como princípio e estratégia de gestão adequada às políticas públicas de promoção e defesa de direitos, como no caso da Política Nacional de Segurança Alimentar e Nutricional. Mas a sua efetiva implementação depende ainda de muitos fatores, devido à complexidade da efetivação de todos os princípios que são agregam a este modelo, pois esse tipo de gestão não deve ser somente reunião de diferentes profissionais com um mesmo objetivo, sem apresentar um diálogo próspero entre os setores e uma proposta de resultados comuns.

Esta estratégia apresenta-se como uma perspectiva inovadora na condução dos serviços ofertados, na reorganização da gestão, viabilizando uma nova relação entre os munícipes e os gestores, considerando-se as peculiaridades locais que poderiam ser levadas em conta no Programa Cozinha 
Comunitária. Este poderia contribuir, por meio de ações intersetoriais, para a melhoria da qualidade de vida a partir do acompanhamento das famílias assistidas através de uma articulação da rede de proteção social, visando o fortalecimento dos direitos, sua efetividade contribuiria para o aperfeiçoamento do programa.

Observa-se nas entrevistas com os gestores a sua dificuldade em operacionalizar os mecanismos da intersetorialidade e sugere-se que este modelo de intervenção requer um envolvimento e compromisso em ações propositivas e conjuntas, em busca de resultados integrados e compromissos em conjunto. Entretanto, observou-se uma disposição para alcançar a realização do trabalho em rede e a busca de parcerias que poderiam ampliar a gestão social do programa e viabilizar o cumprimento das ações propostas na matriz operacional do Plano Integrado de Segurança Alimentar e Nutricional Sustentável.

Considera-se que a busca da efetivação da intersetorialidade não é algo que poderia ocorrer de maneira natural, nem tampouco espontaneamente. Para tal, seriam necessários: compromisso pessoal; compromisso com projetos sociais; formação continuada para aqueles envolvidos no serviço, visando implicação pessoal no processo; integração das ações desenvolvidas pelos diversos serviços, por meio da efetivação de um plano de ação; diálogo, comunicação e envolvimento; participação dos usuários e de suas famílias; compreensão das políticas como direito social; assimilação das implicações da gestão social; e, não menos importante, a efetivação das três dimensões do trabalho intersetorial.

Efetivando estas premissas no eixo da segurança alimentar, poderia ser incorporado, ao planejamento do programa Cozinha Comunitária, um trabalho integrado com os demais serviços. Seria uma ação promissora para tornar este programa uma "boa prática" se tornando referência para a condução de ações para a promoção da qualidade de vidas das famílias em condições de vulnerabilidade social, visando seu empoderamento e emancipação.

Por tudo o que foi discutido neste artigo, podese compreender que o interesse está não apenas em saber se há uma ação suficientemente ampla e eficiente para suprir o DHAA, mas, também, para ampliar o horizonte e avançar na defesa dos direitos de cidadania. Trata-se, portanto, de colocar em prática um dispositivo estratégico visando a intersetorialidade, mas em uma perspectiva mais ampla, visando à garantia dos direitos humanos, em sua natureza inalienável, indivisível e universal.

Deve-se levar em consideração, na construção da intersetorialidade dos programas de SAN, que o seu público está dentre os mais vulneráveis, conforme apontaram os dados da presente pesquisa. A focalização das ações pode implicar em formas assistencialistas e não participativas implicando em retrocesso nos avanços das políticas públicas após a Constituição de 1988. Ações intersetoriais de inclusão social dos beneficiários e de seu acompanhamento na rede poderiam contrabalançar os efeitos adversos da focalização. Isto implica não apenas na inserção dos usuários nos demais serviços da rede, mas no estímulo à participação da sociedade civil organizada no combate à fome.

O desafio está posto: garantir o DHAA exige que gestores e técnicos avancem no desafio da coordenação intersetorial para definição de prioridades, ações, responsabilidades e coerência entre as ações planejadas em comum. Além disso, torna-se importante incentivar a participação dos usuários, através das entidades de controle democrático. Esta é uma discussão que está longe de se esgotar, mas que ora se impõe como busca de efetivação de um modelo de gestão que possa contribuir para uma sociedade justa e emancipada.

\section{REFERÊNCIAS}

[1] Vasconcelos G de, Assis F de. Avaliação nutricional de coletividades. 4.ed. Florianópolis: Editora UFSC; 2008.

[2] Burity V, Franceschini T, Valente F, Recine E, Leão M, Carvalho MF. Direito humano à alimentação adequada no contexto da segurança alimentar e nutricional. Brasília (DF): ABRANDH; 2010.

[3] Abramovay R. O que é fome. São Paulo: Brasiliense; 1991.

[4] Organização das Nações Unidas - ONU. Declaração Universal dos Direitos Humanos (1948) [internet]. 2009 [acesso em 12 jul 2016]. Disponível em http://www.dudh.org.br

[5] Buarque SC. Construindo o desenvolvimento local sustentável. 4.ed. Rio de Janeiro: Garamond; 2001. 
[6] Brasil. Construção do Sistema e da Política Nacional de Segurança Alimentar e Nutricional: a experiência brasileira. Brasilia; 2009

[7] Brasil. Constituição (1988). Ementa constitucional no 64, de 04 de fevereiro de 2010. Altera o art. oo da Constituição Federal, para introduzir a alimentação como direito social. 2010.

[8] Junqueira LAP. Descentralização, intersetorialidade e rede como estratégias de gestão da cidade. Revista FEA-PUC-SP. 1999;1:57-72.

[9] Inojosa RM. Sinergia em políticas e serviços públicos: desenvolvimento social com intersetorialidade. Cadernos Fundap. 2001;22:102-110.
[10] Silveira C. Desenvolvimento local e novos arranjos socioinstitucionais: algumas referências para a questão da governança. In: Dowbor L, Pochmann M. Políticas para o Desenvolvimento Local. São Paulo: Perseu Abramo; 2010. p.4165.

[11] Maia M. Gestão Social: reconhecendo e construindo referências. Textos \& Contextos. 2005;4:1-18.

[12] Garajau NI. Articulação intersetorial: uma estratégia de gestão social para o pograma cozinha comunitária [dissertação]. Belo Horizonte: UNA; 2013.

[13] Brasil. Ministério de Desenvolvimento Social e Combate à Fome. Revista de SAN - Trajetória e Relatos da Construção de uma Política Nacional. Brasília (DF); 2008. 